\title{
X-linked scapuloperoneal syndrome
}

\author{
P. K. THOMAS, D. B. CALNE, ${ }^{1}$ AND C. F. ELLIOTT ${ }^{2}$ \\ From the Department of Neurology, the Royal Free Hospital, and \\ the Royal National Orthopaedic Hospital, London
}

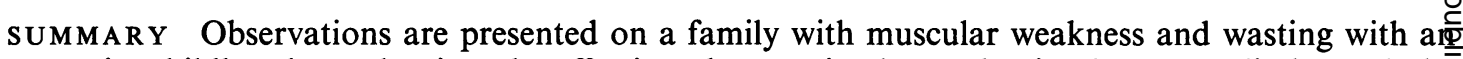
onset in childhood, predominantly affecting the proximal muscles in the upper limbs and the distal muscles in the lower. This was accompanied by contractures of the elbows and by pes cavus Pseudohypertrophy was absent. Progression was slow, but an associated cardiomyopathy de veloped in adult life. Investigations favoured a myopathic basis. The inheritance was of X-linked recessive pattern and the disorder was linked with deutan colour blindness. The clinical features in this family appear to be distinctive and it is likely that the disorder represents a separate clinicad entity.

Cases of muscular weakness and wasting affecting the proximal musculature in the upper limbs and the distal muscles in the lower have been recognized for many years, perhaps the first description being that of Brossard (1886). Particular interest in such cases was shown by Dawidenkow (1927, 1929, 1939). He drew attention to patients with muscular involvement of this distribution, considered to be the result of a denervating process, which commonly began in early adult life. This was usually associated with pes cavus and distal sensory loss in the limbs. The disorder displayed an autosomal dominant pattern of inheritance. It has been considered to exhibit clinical affinities with Charcot-Marie-Tooth disease (Wilson, 1940). Subsequent reports, however, suggested that the 'scapuloperoneal syndrome' does not represent a single entity. Kaeser (1965) described a family in which there was no accompanying sensory loss but which also displayed an autosomal dominant inheritance, and which was believed to be due to a slowly progressive spinal muscular atrophy. A similar family was reported by Ricker and Mertens (1968) and additional cases have been described by Emery, Fenichel, and Eng (1968), Meadows and Marsden (1969), and Schuchmann (1970). Other reports have indicated a myopathic basis. Seitz (1957) and Hausmanowa-Petrusewicz and Zielińska (1962) recorded sporadic cases of the scapuloperoneal

\footnotetext{
1 Present address: Hammersmith Hospital, London.

2 Present address: Lidcombe State Hospital, Sydney, Australia.
}

syndrome considered to be of myopathic origin and Ricker and Mertens (1968) stated that this pattern of muscle disturbance could be en countered in the facioscapulohumeral form of muscular dystrophy. Some of the earlier repots such as that by Oransky (1927), are difficultot assess because of the absence of histologicaloor. electromyographic studies, although Eisenls क्षin (1889) considered his case to be a myopathy histological grounds.

In this communication, we report observations on a family in which the affected member? exhibited a slowly progressive disorder beginnin in childhood, affecting the proximal muscles in the upper limbs and the distal muscles in the lower, and which was associated with a cardio? myopathy. The inheritance was of X-linke recessive pattern and the disorder was linkes with colour blindness.

\section{CASE REPORTS}

The pedigree of the family is given in Fig. 1. In the case histories given below, the individuals are identified by the numeration given in this Figure All living relatives of the propositus have beew examined personally, but serum enzyme estimation and electromyographic and electrocardiographio studies were performed only on the propositus? Adequate hospital records were obtained for twळ్ affected relatives who had died. Three subjects (cases V.8 to 10) were too young for the testing of colour vision to be possible.

CASE IV.13; MALE, AGED 34 YeARS, PROPOSITUS The 

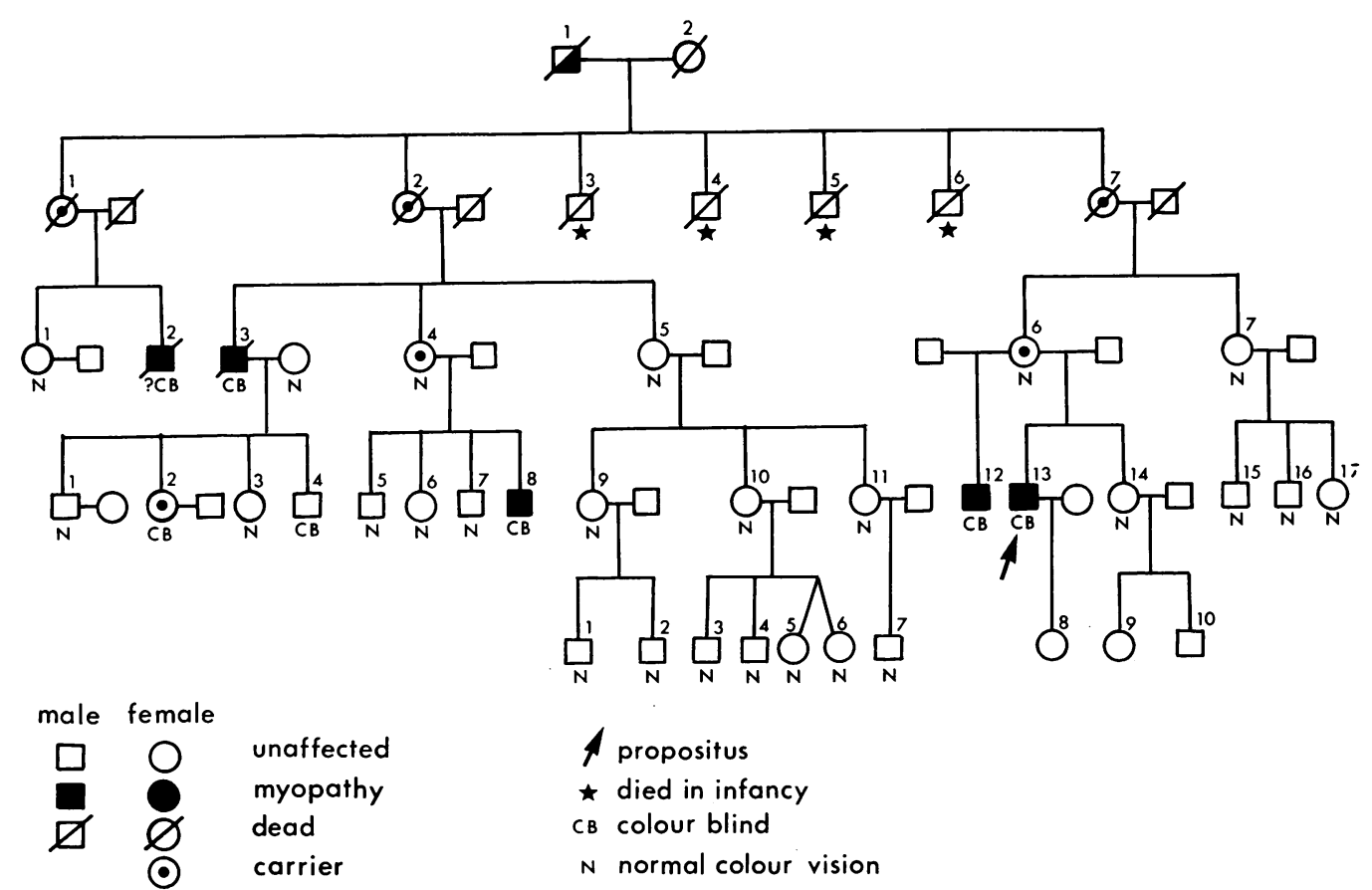

dead, possibly affected

FIG. 1. Pedigree

index case (Fig. 2) was a motor mechanic. It had been noticed in early childhood that extension of his elbows was limited and that he had difficulty in flexing his neck. At the age of 11 years, he began to 'walk on his toes', and subsequently he has had slowly increasing difficulty in walking. This was partially relieved by bilateral surgical elongation of the calcaneal tendons performed in 1964. At present, he is unable to run, but can walk for reasonable distances, although his ankles tend to turn into inversion. He became aware of weakness in his arms when he was in his mid-teens, and this has also slowly increased in severity. He has suffered from recurrent dislocations of both shoulders.

A soft systolic murmur was discovered in the pulmonary area in 1964 and in June 1968 he developed atrial fibrillation after a throat infection. Cardiological examination (Dr. M. K. Towers) again revealed a pulmonary systolic murmur but no other abnormality and there were no cardiological symptoms. An electrocardiogram confirmed atrial fibrillation, but was otherwise unremarkable. Radiography of the chest showed a normal cardiac outline.

Neurological examination demonstrated deutan colour blindness (Ishihara charts and American Optical H-R-R pseudoisochromatic plates) and mild bilateral ptosis. Otherwise the cranial nerves were normal. There was no facial weakness and his sternomastoid muscles were of normal bulk and power. Forward flexion of his neck was limited to about $15^{\circ}$ of movement. There was slight bilateral wasting of the scapular and deltoid muscles, and considerable wasting of biceps and triceps muscles. Elbow extension was limited by muscular contractures to approximately $120^{\circ}$ on the right and $150^{\circ}$ on the left. He showed moderate weakness of supraspinatus and infraspinatus muscles, slightly more marked on the right, but no other weakness of the scapular muscles. There was mild symmetrical weakness of the deltoid muscles, severe weakness of biceps, and slightly less severe weakness of triceps muscles. The wrist and finger extensors were of minimally reduced power on both sides and there was mild weakness of the thenar group on the left. Otherwise, the forearm muscles and small muscles of the hands were of normal strength and there was no weakness of the trunk musculature. In the legs, muscle bulk in the thighs was normal, but the lower leg muscles were grossly wasted with the exception of the extensor digitorum brevis muscles, both of which were normally developed. He showed no proximal weakness, but dorsiflexion at the ankles and toe extension were severely weakened, and ankle eversion was absent. The calf muscles were of normal power. The tendon reflexes were absent in the arms and legs, the abdominal reflexes all obtainable and the plantar responses flexor. He showed no sensory loss. There was bilateral pes cavus. 

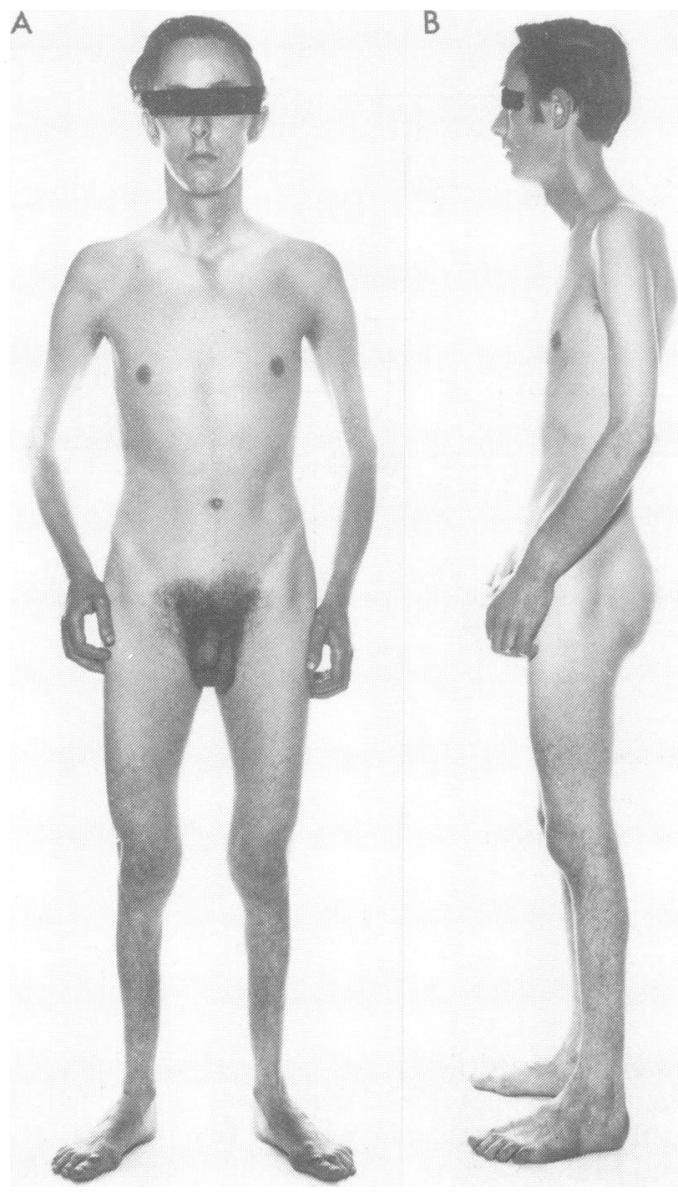

FIG. 2. Case IV.13 (propositus). The distal wasting in the legs is well shown in $A$, and the proximal wasting in the arms in $B$.

The serum creatine kinase level was increased (225 i.u.). Electromyography of the left biceps brachii and tibialis anterior muscles, recorded through a concentric needle electrode, revealed no abnormal insertion activity or spontaneous electrical activity. In both muscles, the motor unit recruitment pattern was slightly reduced. Individual motor unit action potentials tended to be brief and polyphasic but were mostly of normal amplitude, although there were areas where they were of reduced amplitude (less than $0.5 \mathrm{mV}$ ). Motor nerve conduction velocity was measured in the left median and left common peroneal nerves. Normal values of 56 and $53 \mathrm{~m} / \mathrm{sec}$ respectively were obtained. On stimulation of the index finger through ring electrodes, a median nerve sensory action potential of normal amplitude $(12 \mu \mathrm{V})$ and velocity $(58 \mathrm{~m} / \mathrm{sec})$ was obtained percutaneously. On stimulation of the left anterior tibial nerve at the ankle, a potential $5 \mu \mathrm{V}$ in amplitude with a velocig of $58 \mathrm{~m} / \mathrm{sec}$ was recorded percutaneously at the knee. These values are also normal.

Quantitative electromyographic studies were par formed by Dr. R. G. Willison, employing the techniques described by Fitch and Willison (1965) and Rose and Willison (1967). 'The right trice muscle was examined with a concentric need electrode at a load of $2 \mathrm{~kg}$. Seventeen areas wete sampled. Individual motor units were highly pol phasic and in some areas a fairly full motor unit pattern was seen even at this load. The number of potential changes per second reached 1397 in ove area and the mean was 798, this figure being great of than nine standard deviations above the mean value for a control group. The mean amplitude for 19 areas was $0.77 \mathrm{mV}$. The maximum voluntary force that could be achieved was $7 \mathrm{~kg}$. The left tibialis anterior muscle was also sampled during moderaf to strong effort. Areas showing over 1000 potenti changes per second were found. In some areas, mea amplitudes of $1.8 \mathrm{mV}$ were observed, but only wigig a full pattern.' It was concluded that the findings were unlike those in neurogenic atrophy and were in favour of a myopathic disorder. The comment wå made that large values for mean amplitude may bs seen in long-standing and slowly progressive muscle disease.

The patient refused to submit to muscle biopso

CASE IV.12; MALE AGED 10 YEARS The half-bro of the propositus did not begin to walk until the age of 19 months and is stated always to have walke 'awkwardly'. At the age of 3 years it was observee that his feet were excessively arched. He has slowfis developed increased difficulty in walking and has been unable to take part in athletic activities af school. He has been unaware of any disability in his arms. There is some intellectual retardation which has not been formally assessed.

Examination revealed deutan colour blindness: His cranial nerves were otherwise normal. There was no limitation of neck flexion. He displayed no obvp ous wasting in the upper limbs and no limitation of elbow extension, but there was mild symmetrical weakness of the supraspinatus, deltoid, biceps, and triceps muscles. There was also no wasting in the legs. Dorsiflexion and eversion were moderatel? weak at both ankles, as was extension of the toess The tendon reflexes were all absent, the planta․ responses were flexor, and there was no sensory los\$̄ Bilateral pes cavus was present.

CASE IV.8; MALE AGED 15 YEARS No abnormalit was detected until the age of 5 years when difficult in walking became evident. This has slowly increase $\phi$ but has not become severe and amounts to a sligh incapacity only. He has recently taken up employ:ment as an engineering apprentice. At about the age 
of 11 years, mild weakness of the upper arms was noticed, together with some limitation of elbow extension.

Examination revealed deutan colour blindness. His face had a slightly 'myopathic' appearance, but there was no detectable weakness. The other cranial nerves were normal and neck flexion was full. $\mathrm{He}$ showed no wasting in the upper limbs, but there was mild bilateral weakness of the biceps and triceps muscles and some restriction of elbow extension. The forearm and small hand muscles were of normal bulk and power. He showed mild wasting of the muscles of the anterolateral compartment of the lower legs with weakness of dorsiflexion and eversion at the ankles and of extension of the toes. The tendon reflexes were absent in the arms, but the knee jerks were normal. The left ankle jerk was depressed and the right absent. Both plantar responses were flexor and there was no sensory loss. Bilateral pes cavus was present.

CASE IV.2; fEMALE AGED 28 yeARS, AND IV.4, MALE AGED 17 YEARS Neither of these individuals had any neurological symptoms and there were no abnormal findings on examination except that both had deutan colour blindness.

CASE III.2; MALE At the age of 45 years the patient was admitted to St. Mary's Hospital, Sidcup, Kent, under the care of Dr. T. L. Reeves, because of severe effort dyspnoea. There was a previous history of bilateral congenital dislocation of the hips for which he received surgical treatment when aged 5 years. He remained with life-long difficulty in walking and had never worked. His sister stated that she believed he was colour blind.

On neurological examination, he was considered to be of reduced intelligence, but this was not formally assessed. The cranial nerves were normal, no facial weakness or weakness of the sternomastoid muscles being detectable. In the upper limbs, wasting of the upper arm muscles and of $\mathrm{m}$. brachioradialis was evident. There was bilateral weakness of the biceps, triceps, and brachioradialis muscles, and possibly also of the deltoid muscles. In the lower limbs, there was bilateral weakness of the quadriceps and hamstring muscles and of dorsiflexion at the ankles. The tendon reflexes were absent in the arms, but sluggish knee and ankle jerks were obtained. The plantar responses were flexor and there was no sensory loss. He had bilateral pes cavus.

Examination of the cardiovascular system revealed congested neck veins, considerable cardiac enlargement, and a systolic murmur in the aortic area. There was tachycardia of 100 per minute with multiple ectopic beats. He was normotensive.

A radiograph of the chest showed a greatly increased transverse cardiac diameter. There was no undue prominence of the aortic knuckle or of the pulmonary vascular markings. Electrocardiography demonstrated sinus rhythm with a variable $P-R$ interval. The QRS complexes were normal, although there were multiple ventricular extrasystoles of bizarre form. The ST segment was isoelectric. The $T$ waves were flattened in standard lead I and in AVL and inverted in leads V5 and V6.

Electromyography was performed at St. Thomas's Hospital (Dr. D. Newton). Biceps brachii, tibialis anterior, peroneus longus, and extensor digitorum brevis muscles were examined. No denervation potentials were detected. The motor unit pattern on volition was found to be reduced in all four muscles. Some of the units in m. biceps were of broken-up appearance, but those in the leg muscles were of large amplitude although their size was not specified. It was considered that these findings favoured denervation but no definite conclusion was reached.

He died suddenly five weeks after admission to hospital. A necropsy was performed by Professor P. M. Daniel. The heart was massively and symmetrically enlarged and weighed $780 \mathrm{~g}$. The ventricular cavities were large; the valves and endocardium were normal. The ventricular walls were not obviously hypertrophied and the heart muscle was of normal and uniform colour. The coronary arteries were normal and there were only very small atheromatous plaques in the lower aorta. Histological examination of the heart showed extensive fibrous replacement of the myocardium.

In the upper limbs, the deltoid, forearm, and hypothenar muscles were macroscopically normal. Both triceps muscles were white and fibrotic, as were the brachialis muscles and the deeper portions of biceps, and the thenar muscles were also pale. In the lower limbs, the thigh muscles were dark as were the anterior compartment muscles of the lower legs, but the calf muscles were white and fibrotic. The findings on histological examination were as follows.

In m. biceps brachii (Fig. 3), there was a grossly increased variation in muscle fibre diameter: some fibres were abnormally large (up to $150 \mu \mathrm{m}$ ), others small and atrophic. There was no clear indication of grouping of the atrophic fibres. There was an increased number of centrally situated nuclei, particularly in fibres of larger diameter. Occasional degenerate fibres surrounded by histiocytes and mononuclear cells were present.

There was a substantially increased quantity of endomysial collagen and fat. Similar but less severe changes were evident in deltoid and tibialis anterior muscles. The sample taken from a gastrocnemius muscle was grossly abnormal, with an almost total replacement by fibrofatty connective tissue, only a few scattered atrophic muscle fibres being present. Milder changes were evident in the sternomastoid, thenar, psoas, and quadriceps femoris muscles. In these muscles (Fig. 4), the range of fibre diameter was abnormally great and there was an increased number 


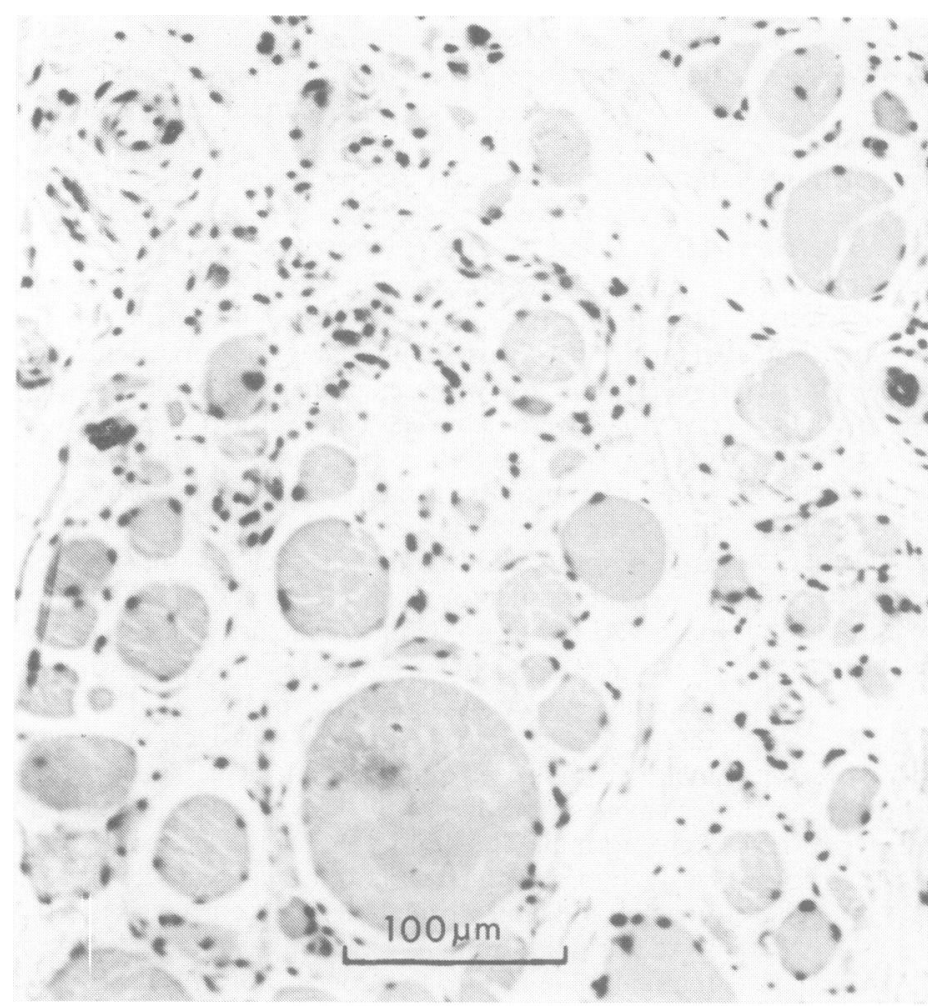

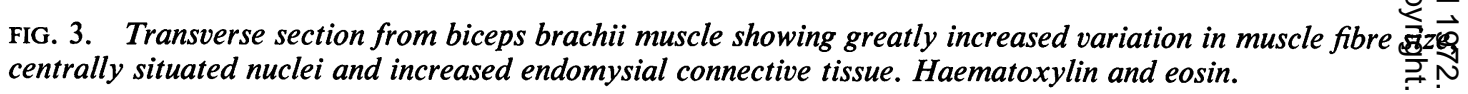

of centrally placed nuclei. There was no indication of grouping of the atrophic fibres.

No abnormality was detected in sections of the sciatic nerve. The density of myelinated nerve fibres appeared entirely normal. The spinal cord was not examined.

CASE III.3; MALE This patient attended the West Herts. Hospital in 1953 when aged 38 years because of a momentary episode of vertigo followed by anarthria for a period of two hours. He had a previous history of having developed difficulty in walking at the age of 10 years, and also deformity of his feet because of which he wore surgical boots. It was stated that his upper arms had 'never developed' and that they had been weak since childhood. In addition, he had had a scoliosis and bilateral limitation of elbow extension since early life. However, he was not greatly handicapped and worked as a publican. He is known to have been colour blind.

On neurological examination, his facial muscles were recorded as being thin, but no weakness was noted. His cranial nerves were otherwise normal. There was weakness and wasting of the shoulder and upper arm muscles and limitation of extension of both elbows, neither of which could be extende beyond $100^{\circ}$. He had scoliosis. In his legs, the lefy lower leg muscles were wasted as compared with the right and bilateral weakness of the peronei was notes The tendon reflexes were all absent in the arms, but present in the legs. The plantar responses were flex and there was no sensory loss. He showed bilaterat. pes cavus. On examination of the cardiovascula system, he was observed to have a bradycardia (3 $40 / \mathrm{min})$ and a greatly enlarged heart, confirmeg radiographically. A late systolic murmur was heard at the apex and left sternal edge. There were no sigis of cardiac failure. His blood pressure was $160 / 80$ mmHg. Electrocardiography (ECG) revealed a slow nodal rhythm with evidence of an interventricular conduction defect, together with ST segment and wave abnormalities. He was seen by Dr. Purdogs Martin at the National Hospital, Queen Square, who confirmed the neurological findings. He considered that the diagnosis was one of myopathy, but neithere electromyography nor muscle biopsy was performed

The patient was admitted to the West Herko Hospital in 1954 with acute left chest pain and signt of mild cardiac failure. A repeat ECG showed ev? dence of ischaemia over the anterior part of the lef形 


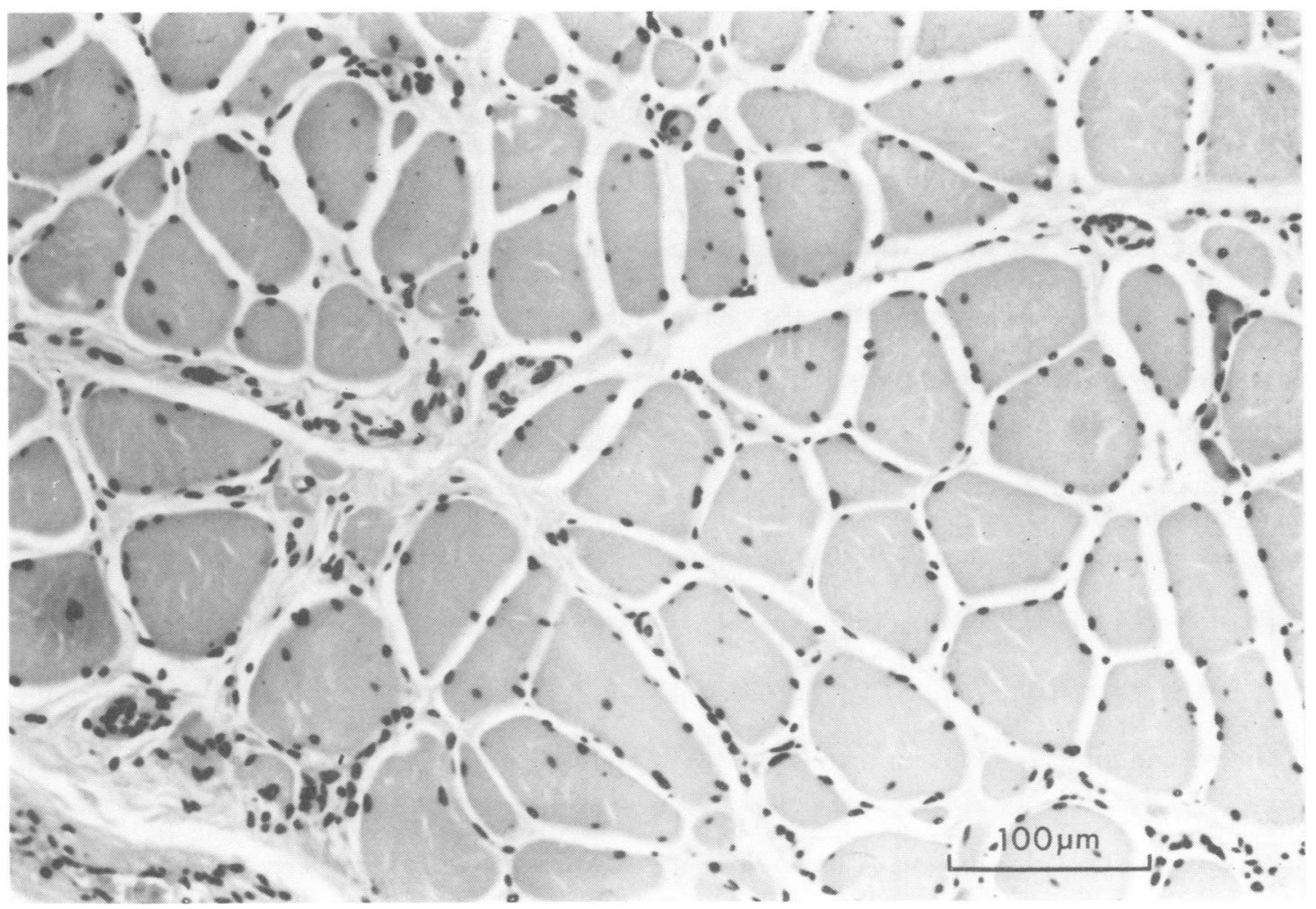

FIG. 4. Transverse section from thenar muscles showing abnormal variation in fibre size and centrally situated nuclei. Haematoxylin and eosin.

ventricle and a radiograph of the chest again showed a greatly enlarged heart. A diagnosis of myocardial infarction was made. He was treated with anticoagulants and made an uneventful recovery, with improvement in the ECG changes.

In .August 1957 he was readmitted with a left hemiparesis of sudden onset, probably embolic in origin, which slowly recovered. After discharge, he was referred to Dr. J. F. Goodwin at Hammersmith Hospital who saw him in October 1967. A two year history of moderate exertional dyspnoea was elicited. A venous pressure of 3 to $4 \mathrm{~cm}$ was noted with occasional cannon waves. His heart was enlarged and a third sound was audible. His blood pressure was $115 / 65 \mathrm{mmHg}$. A radiograph of the chest showed a large heart with enlargement of both atria and the left ventricle. Dr. Goodwin considered that he had a cardiomyopathy. He proposed admission for further investigation, but the patient died suddenly at home before this was arranged. A necropsy was not performed.

CASE I.1; MALE No definite details are known about this individual except that he suffered from muscular weakness. He died at the age of 38 years and his death certificate records the cause of death as paralysis. The family were aware that a male cousin of his also suffered from muscular paralysis and became confined to a wheel-chair.

\section{DISCUSSION}

Previous reports of patients with muscular involvement of scapuloperoneal distribution have made it clear that there is often difficulty in deciding whether the process is myopathic or neurogenic. Thus in the family reported by Kaeser (1965), electromyography (EMG) on case V.21 on one occasion yielded findings suggestive of denervation and on another of myopathy. A muscle biopsy was considered to indicate myopathy. In case IV.8, on whom a necropsy examination was performed, the histological changes in affected muscles were consistent with denervation atrophy, and the loss of anterior horn cells and of cells in the lower brain-stem motor nuclei was believed to provide conclusive evidence of a neurogenic 
process. Also in another family in which the same diagnosis was made (Ricker and Mertens, 1968, case 1), EMG of the shoulder and upper arm muscles suggested myopathy, whereas, in the lower leg, the appearances were those of denervation. Kaeser (1965) suggested that the myopathic changes in the EMG might be the result of a degeneration of the motor neurone beginning in a patchy manner in the nerve terminals at the periphery, leading to a thinning out of muscle fibres from the motor unit and thus producing pseudo-myopathic appearances in the EMG. The difficulty in deciding between a myopathic and neurogenic basis in cases of the scapuloperoneal syndrome has been stressed by Feigenbaum and Munsat (1970). Their series included cases with findings commonly attributed both to neurogenic and myopathic processes.

In the present family, the EMG changes in case III.2 were equivocal. The histological findings in the muscles obtained at necropsy, however, undoubtedly favour a myopathy. It is possible that secondary myopathic changes may develop as a consequence of long-standing denervation (Brodal, Böyesen, and Frövig, 1953; Haase and Shy, 1960; Drachman, Murphy, Nigam, and Hills, 1967). This is not likely to be the explanation here, as mildly involved muscles, such as the psoas and the thenar muscles, showed a random arrangement of large and small fibres without any indication of grouping of the small fibres. The spinal cord was not examined, but the sciatic nerve showed no abnormality, despite the fact that both the calf and the anterior tibial group muscles were severely affected. In the propositus of this family (case IV.13), the EMG findings were those of myopathy and not of denervation.

The inheritance in the present family is almost certainly of X-linked recessive pattern (Fig. 1). All affected individuals were male and the disorder was transmitted by unaffected females. Transmission from an affected male (case I.1) through carrier females possibly occurred. Support for the view that the disorder is X-linked is provided by the fact that all the affected individuals were colour blind, although this is not entirely certain for case III.2. A complicating feature is that cases IV.2 and IV.4, who were unaffected female and male children respectively of an affected male (case III.3), were both colour blind. It seems likely that their mother was a carrier for colour blindness; however, it was possible to examine only one of her male rela- tives, who had normal colour vision. In view ow the linkage of the disorder with colour blind ness, it is probable that case IV.2 is a carriers There was no clinical evidence of Turner syndrome (XO constitution): she was of norma stature and examination revealed none of the other features of this condition.

As already mentioned, the weight of the evis. dence in the present family suggests a myo pathic disorder, although it cannot be con? sidered that this has been fully established. ThE common form of X-linked muscular dystroph $\overline{\bar{p}}$. is the Duchenne type and it is now clear that the more benign Becker type (Becker, 1957, 1962\% Becker and Keiner, 1955) is a separate entity. It is possible that the benign form is capable of further subdivision (Shaw and Dreifuss, 1969) Mabry, Roeckel, Munich, and Robertson (1965 and Emery and Dreifuss (1966) described fam lies for which it was felt that the clinical featuresu were sufficiently different from the Becker typê to merit their being considered as separate formis of benign X-linked dystrophy.

Neither the Duchenne nor the Becker form of muscular dystrophy are closely linked wit colour blindness. There is only a single defirte description of genetic linkage between colषur blindness and Duchenne dystrophy (Eme्gis 1966). The family reported by Philip, Waltơn, and Smith (1956) as Duchenne dystrophy im which crossing-over with colour blindness was demonstrated is stated by Kloepfer and Emeri (1969) to have a benign form of X-linkeक्ष dystrophy.

All these varieties have in common the initia involvement of proximal muscles. The present family is distinct in displaying proximal involve ment in the upper limbs and distal in the lowe The onset was in early childhood, probably at of before the age of 5 years in all instances, and progression was uniformly slow. Contractures of the elbows were present in all except one cases and pes cavus in all. The limitation of neck flexion in the propositus was an interestine finding. Pseudohypertrophy of muscle was con? spicuously absent, the affected muscles tendin to be of small bulk with a firm, rubbery consist ence. Slight facial involvement was possible but not definite. Cardiomyopathy was a feature of the three adult cases and was the probable cause of death in one of the two that died (case III. and possibly also in the other (case III.3). The two young affected cases (IV.8 and 12) had ne clinical evidence of cardiac disorder, bup 
electrocardiograms were not obtained. It may be significant that two affected individuals were of subnormal intelligence (cases IV.8 and III.2) in view of the known occurrence of mental retardation in some cases of muscular dystrophy (Allen and Rodgin, 1960; Worden and Vignos, 1962).

Certain of the clinical features of this family resemble those of the family described by Emery and Dreifuss (1966), in particular, the early age of onset, the occurrence of contractures of the elbows and of the calf muscles, the absence of pseudo-hypertrophy, and the occurrence of cardiomyopathy. As already emphasized, however, the pattern of involvement of the skeletal musculature was quite different.

We wish to thank Mr. Alec Benjamin for referring the family, Dr. Gregory Stewart for helpful discussion on the genetic aspects, and Miss Ann Armstrong for technical assistance. We are indebted to Dr. M. K. Towers for information on case IV.13 and Dr. T. L. Reeves and Dr. R. Hierons for details about case III.2. Professor P. M. Daniel, Dr. I. Janota, and Dr. S. Strich kindly made available the necropsy findings and allowed us to examine histological material from this case. We are also indebted to Dr. J. Purdon Martin for information about case III.3, and to Dr. R. G. Willison for electromyographic studies on case IV.13. Finally, financial support from the Wellcome Trust and the Muscular Dystrophy Group of Great Britain, and an equipment grant from the Medical Research Council, are gratefully acknowledged.

\section{REFERENCES}

Allen, J. E., and Rodgin, D. W. (1960). Mental retardation in association with progressive muscular dystrophy. American Journal of Diseases of Children, 100, 208-211.

Becker, P. E. (1957). Neue Ergebnisse der Genetik der Muskeldystrophien. Acta Genetica et Statistica Medica, 7, 303-310.

Becker, P. E. (1962). Two new families of benign sex-linked recessive muscular dystrophy. Revue Canadienne de Biologie, 21, 551-566.

Becker, P. E., and Keiner, F. (1955). Eine neue X-chromosomale Muskeldystrophie. Archiv für Psychiatrie und Nervenkrankheiten vereinigt mit Zeitschrift fïr die gesamte Neurologie und Psychiatrie, 193, 427-448.

Brodal, A., Böyesen, S., and Frövig, A. G. (1953). Progressive neuropathic (peroneal) muscular atrophy (CharcotMarie-Tooth disease). Histological findings in muscle biopsy specimens in fourteen cases, with notes on clinical diagnosis and familial occurrence. Archives of Neurology and Psychiatry, 70, 1-29.

Brossard, J. (1886). Étude Clinique sur une Forme Héréditaire d'Atrophie Musculaire Progressive Débutant parles Membres Inférieurs (Type Fémoral acec Griffes des Orteils). Steinheil: Paris.

Dawidenkow, S. (1927). Über die neurotische Muskel- atrophie Charcot-Marie. Klinisch-genetische Studien. Zeitschrift fïr die gesamte Neurologie und Psychiatrie, 107, 259-320.

Dawidenkow, S. (1929). Über die scapulo-peroneal Amyotrophie. Zeitschrift fiur die gesamte Neurologie und Psychiatrie, 122, 628-650.

Dawidenkow, S. (1939). Scapuloperoneal amyotrophy. Archives of Neurology and Psychiatry, 41, 694-701.

Drachman, D. B., Murphy, S. R., Nigam, M. P., and Hills, J. R. (1967). ' Myopathic' changes in chronically denervated muscle. Archives of Neurology, 16, 14-24.

Eisenlohr, C. (1889). Ueber progressive muskelatrophie. Neurologisches Zentralblatt, 8, 564-565.

Emery, A. E. H. (1966). Genetic linkage between the loci for colour blindness and Duchenne type muscular dystrophy. Journal of Medical Genetics, 3, 92-95.

Emery, A. E. H., and Dreifuss, F. E. (1966). Unusual type of benign X-linked muscular dystrophy. Journal of Neurology, Neurosurgery, and Psychiatry, 29, 338-342.

Emery, E. S., Fenichel, C. M., and Eng, G. (1968). A spinal muscular atrophy with scapuloperoneal distribution. Archives of Neurology, 18, 129-133.

Feigenbaum, J. A., and Munsat, T. L. (1970). A neuromuscular syndrome of scapulo-peroneal distribution. Bulletin of the Los Angeles Neurological Society, 35, 47-57.

Fitch, P., and Willison, R. G. (1965). Automatic measurement of the human electromyogram. Journal of Physiology, 178, 28-29P.

Haase, G. R., and Shy, G. M. (1960). Pathological changes in muscle biopsies from patients with peroneal muscular atrophy. Brain, 83, 631-637.

Hausmanowa-Petrusewicz, I., and Zielińska, S. (1962). Zur nosologischen Stellung des scapulo-peronealen Syndroms. Deutsche Zeitschrift fiur Nervenheilkunde, 183, 377-382.

Kaeser, H. E. (1965). Scapuloperoneal muscular atrophy. Brain, 88, 407-418.

Kloepfer, H. W., and Emery, A. E. H. (1969). Genetic aspects of neuromuscular disease. In Disorders of Voluntary Muscle, 2nd edn, pp. 683-712. Edited by J. N. Walton. Churchill: London.

Mabry, C. C., Roeckel, I. E., Munich, R. L., and Robertson, D. (1965). X-linked pseudohypertrophic muscular dystrophy with a late onset and slow progression. New England Journal of Medicine, 273, 1062-1070.

Meadows, J. C., and Marsden, C. D. (1969). Scapuloperoneal amyotrophy. Archives of Neurology, 20, 9-12.

Oransky, W. (1927). Über einen hereditären typus progressiver Muskeldystrophie. Deutsche Zeitschrift für Nercenheilkunde, 99, 147-155.

Philip, U., Walton, J. N., and Smith, C. A. B. (1956). Colour blindness and the Duchenne-type muscular dystrophy. Annals of Human Genetics, 21, 155-158.

Ricker, K., and Mertens, H. G. (1968). The differential diagnosis of the myogenic (facio)-scapulo-peroneal syndrome. European Neurology, 1, 275-307.

Rose, A. L., and Willison, R. G. (1967). Quantitative electromyography using automatic analysis: studies in heaithy subjects and in patients with primary muscle diseases. Journal of Neurology, Neurosurgery, and Psychiatry, 30, 403-410.

Schuchmann, L. (1970). Spinal muscular atrophy of the scapulo-peroneal-type. Zeitschrift für Kinderheilkunde, $109,118-123$.

Seitz, D. (1957). Zur nosologischen Stellung des sogenannten scapulo-peronealen Syndroms. Deutsche Zeitschrift für Nervenheilkunde, 175, 547-552.

Shaw, R. F., and Dreifuss, F. E. (1969). Mild and severe forms of X-linked muscular dystrophy. Archices of Neurology, 20, 451-460.

Wilson, S. A. Kinnier (1940). Neurology. Edited by A. Ninian Bruce. Arnold: London.

Worden, D. K., and Vignos, P. J. (1962). Intellectual function in childhood progressive muscular dystrophy. Pediatrics, 29, 968-977. 